\title{
Three-dimensional computed tomography angiography for the preoperative evaluation of coronary artery disease in lung cancer patients
}

\author{
Fumiaki Watanabe ${ }^{1}$, Osamu Hataji', Kentaro Ito' ${ }^{1}$, Corina N D'Alessandro-Gabazza ${ }^{3}$, Masahiro Naito ${ }^{1}$, Hideo Morooka ${ }^{3}$, \\ Esteban C Gabazza ${ }^{4 *}$, Yukio Mizutani ${ }^{2}$, Maki Ohi ${ }^{2}$, Motoshi Takao ${ }^{5}$, Hideto Shimpo ${ }^{5}$ and Isao Yada ${ }^{1}$
}

\begin{abstract}
Background: The number of elderly patients undergoing surgery for lung cancer is increasing. In this study, we assessed the usefulness of three-dimensional computed tomographicangiography (3D-CTA) for the detection of coronary disease in the elderly before surgical intervention for lung cancer.

Methods: One hundred twenty patients admitted to our institution for lung cancer resection were enrolled in the study. 3D-CTA was performed in all 120 patients.

Results: Seventy-one patients had normal findings, and forty-nine patients showed coronary stenosis on 3D-CTA examination. Among the latter 49 patients, 24 with slight stenosis underwent lung tumor resection, 23 had coronary angiography for severe stenosis before lung surgery and 2 were not eligible for lung resection because of very severe coronary stenosis. The diagnostic value of 3D-CTA was better than conventional CT.
\end{abstract}

Conclusions: This study suggests the usefulness of 3D-CTA for the preoperative diagnosis of coronary ischemic disease in elderly lung cancer patients.

Keywords: Aging, Coronary ischemic disease, Lung cancer, Surgery

\section{Background}

The aging population is increasing in developed countries, including the United States, Canada and Australia as well as European countries, and the increase is even greater in Japan [1-3]. Although prolonged life expectancy is one of the biggest achievements of humankind, expansion of the oldest population also implies a rise in age-related diseases, including malignancies and cardiovascular disorders [1]. Among malignant diseases in the aging population, lung cancer is the leading cause of death in Japan and worldwide [4-6]. Patients with lung cancer have a poor prognosis, with only $15 \%$ of them being eligible for surgical resection $[4,6]$. Although the therapeutic response is limited, patients with advanced disease are usually treated with systemic chemotherapy or tyrosine inhibitors $[4,6]$.

\footnotetext{
*Correspondence: gabazza@doc.medic.mie-u.ac.jp

${ }^{4}$ Department of Immunology, Mie University Faculty and Graduate School of Medicine, Edobashi 2-174Mie 514-8507 Tsu City, Japan

Full list of author information is available at the end of the article
}

In Japan, surgery is not usually indicated as a therapeutic option for the oldest group of lung cancer patients (older than 80years of age) because of poor performance status $[7,8]$. Because the performance status of some elderly groups with lung cancer has dramatically improved, aging is no longer an exclusion criterion for surgical intervention. However, the presence of concomitant diseases, such as emphysema, high blood arterial hypertension, coronary ischemic disease, cerebrovascular disorders and diabetes mellitus, are not uncommon in the elderly. Therefore, a meticulous presurgical examination is critical to avoiding complications during and after surgery [9-11]. In particular, the risk of complications is much higher in the elderly people with coronary disease associated with diabetes mellitus or the metabolic syndrome [12].

In the present study, we evaluated the usefulness of three-dimensional computed tomographicangiography (3D-CTA) for the detection of coronary disease in the elderly before surgical intervention for lung cancer.

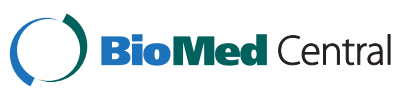




\section{Methods}

One hundred twenty patients (69 males, and51 females; mean age, $71.4 \pm 9.0$ years old) admitted to our institution from 1 November 2009 through 30 September 2012 for surgical intervention of lung tumors were enrolled in the study. Among all patients, 111 had primary lung cancer, 2 had atypical adenomatous hyperplasia and 7 had metastatic lung tumors spread from other distal organ primary tumors. The histological type of the lung primary tumors was as follows: 86 adenocarcinomas, 19 epidermoid carcinomas, 1 large-cell carcinoma, 3 small cell carcinomas and 2 multiple lung cancers. The lung cancer stages were as follows: IA, 71 patients; IB, 20; IIA, 8; IIB, 2; IIIA, 4; IIIb, 2; and IV, 4 patients. Other underlying diseases of the patients and smoking history are described in Table 1.

A high-resolution CT scanner, the Philips Brilliance iCT (Philips Healthcare, Best, The Netherlands) with both 128- and 256-slice configurations, was used. The scanning parameters were as follows: $0.625 \mathrm{~mm}$ collimation $\times 128$, pitch 0.14 , rotation time $0.27 \mathrm{~s}$, thickness $0.8 \mathrm{~mm}$ and slice increment $0.4 \mathrm{~mm}$. The Nemoto Dual Shot contrast injector (NemotoKyorindo Co, Ltd, Tokyo, Japan) was used for contrast administration. An electrocardiography gated volume scan was performed to assess coronary and pulmonary arteries at the same time. The whole lungs were scanned and photographed after a breath hold. The timing to start scanning was determined by using the bolus tracking method. The ascending aorta was taken as the region of interest, and the scan imaging was started when the CT values reached 100. CT data were transferred to an imaging analysis system (Extended Brilliance Workspace; Philips Healthcare) for image reconstruction.

Table 1 Characteristics of the patients with normal and abnormal 3D-CTA findings ${ }^{a}$

\begin{tabular}{|c|c|c|c|c|}
\hline & \multicolumn{2}{|c|}{$\begin{array}{l}\text { Patients with } \\
\text { normal 3D-CTA } \\
\text { findings }(n=71)\end{array}$} & \multicolumn{2}{|c|}{$\begin{array}{c}\text { Patients with } \\
\text { abnormal 3D-CTA } \\
\text { findings ( } n=49)\end{array}$} \\
\hline & Number & (\%) & Number & (\%) \\
\hline \multicolumn{5}{|l|}{ Sex } \\
\hline Male & 36 & $(50.7)$ & 33 & $(67.3)$ \\
\hline Female & 35 & $(49.3)$ & 16 & $(32.7)$ \\
\hline \multicolumn{5}{|l|}{ Age } \\
\hline$>75$ years old & 26 & $(36.6)$ & 27 & $(55.1)$ \\
\hline Smoking $(+)$ & 31 & $(43.7)$ & 33 & (67.3) \\
\hline \multicolumn{5}{|l|}{ Underlying disorders } \\
\hline Diabetes mellitus & 5 & $(7.0)$ & 11 & $(22.4)$ \\
\hline Arterial hypertension & 26 & (36.6) & 26 & $(53.1)$ \\
\hline Hyperlipidemia & 15 & $(21.1)$ & 9 & (18.4) \\
\hline
\end{tabular}

${ }^{a}$ 3D-CTA, three-dimensional computed tomographicangiography.
The presence of calcification visualized by conventional CT was evaluated and classified as grade 0 , no calcification; grade 1, calcification in one arterial branch or diffuse calcification; grade 2, calcification in two arterial branches; and grade 3, calcification in three or more branches. Written informed consent was obtained from each patient before the beginning of the study.

\section{Results}

Preoperative examination with 3D-CTA was performed in 120 patients. Of these, 71 showed normal findings and $49(40.8 \%)$ showed coronary stenosis. The grade of coronary stenosis in these 49 patients was slight in 24 patients and severe in 25 patients. Patients $(n=24 ; 48.9 \%)$ with a slight grade of coronary stenosis based on 3DCTA findings underwent lung tumor resection. Among the patients with severe coronary stenosis, 23 (46.9\%) underwent coronary angiography before lung surgery and 2 (4.2\%) were considered ineligible for lung resection.

Among the 23 patients who under went coronary angiography, percutaneous coronary intervention (PCI) (diagnostic yield 69.5\%) was indicated in 16 patients, and in 7 patients this intervention was considered unnecessary. Of 16 patients with indications for PCI, 1 had surgery after placement of a bare metal stent and the remaining 15 underwent lung resection while receiving continuous infusion of a vasodilator (nicorandil). PCI was scheduled in the latter 15 patients in a watch-and-wait fashion. In our hospital, stent implantation is performed in all angioplasty interventions. The coronary arteries that were surgically treated in 16 cases were as follows: anterior descending branch (8 cases), circumflex branch (4 cases), right coronary artery (1 case), anterior descending branch plus diagonal branch (1 case), anterior descending branch plus right coronary artery (1 case)and anterior descending branch plus right coronary artery plus circumflex branch (1 case).

Conventional CT showed only findings of calcification grade 0 or 1 in 11 patients judged as having severe coronary stenosis on the basis of3D-CTA and in 7 patients who actually required PCI (Table 2 and Figure 1). Furthermore, coronary angiography was not indicated in three patients with calcification grade 3 ascertained by conventional CT, because the 3D-CTA study showed no stenosis. The need of PCI was not possible to judge solely on the basis of conventional CT findings.

\section{Discussion}

In this study, we have shown the usefulness of 3D-CTA for the detection of asymptomatic coronary ischemic disease in elderly patients before surgical resection of lung tumors. In an attempt to prevent coronary events during the perioperative period, several guidelines for perioperative cardiovascular assessment have been estab- 
Table 2 Relationship between 3D-CTA and conventional CT grading ${ }^{a}$

\begin{tabular}{lccccc}
\hline \multicolumn{7}{c}{ 3D-CTA } \\
\hline Conventional & Normal & Slight & Severe & PCI & $\begin{array}{c}\text { Ineligible for lung } \\
\text { resection }\end{array}$ \\
CT grading & $(\boldsymbol{n}=\mathbf{7 1})$ & $(\boldsymbol{n}=\mathbf{2 4})$ & $(\boldsymbol{n}=\mathbf{2 5})$ & $(\boldsymbol{n}=\mathbf{1 6})$ & $(\boldsymbol{n}=\mathbf{2})$ \\
\hline Grade 0 & 46 & 7 & 4 & 3 & 0 \\
Grade 1 & 17 & 11 & 7 & 4 & 0 \\
Grade 2 & 5 & 5 & 8 & 4 & 1 \\
Grade 3 & 3 & 1 & 6 & 5 & 1
\end{tabular}

a 3D-CTA, three-dimensional computed tomographic angiography; normal grade, no calcification; slight grade, calcification in 1 vessel; moderate grade, calcification in two vessels; severe grade, calcification in three or more vessels; $\mathrm{PCl}$, percutaneous coronary intervention.

lished before patients undergo noncardiac surgery [13-15]. Owing to the poor positive predictive value of noninvasive cardiac stress tests for perioperative evaluation, it is often necessary in some patients to use alternative but invasive procedures to make decisions about whether to perform preoperative coronary revascularization before elective noncardiac surgery [16]. The perioperative risk of coronary artery disease, including myocardial infarction, cardiac arrhythmia and cardiac arrest, is high in patients undergoing surgery. The precise mechanism of myocardial ischemic events during the perioperative period is unclear, but surgical stress-associated myocardial ischemia and/ or rupture of coronary atherosclerotic plaque are believed to play critical roles $[17,18]$.

The recent advances in the technology of multislice CT have expanded the clinical application of CT scanning as a tool for the diagnosis of several diseases, including cardiovascular disorders [19-22]. Furthermore, analysis using imaging system software has allowed the threedimensional reconstruction of vascular branches by providing images with quality even better than images obtained using conventional angiography $[21,22]$. In the present study, we used 3D-CTA for preoperative evaluation of coronary ischemic disease in agroup of elderly lung cancer patients with surgical indications. 3D-CTA showed the presence of coronary stenosis in almost half of the cases, and many of them required PCI. Surgical procedures in subjects with coronary atherosclerotic disease are associated with the risk of morbidity and mortality in the perioperative period $[17,23]$. Therefore, the results of the present study strengthen the value of 3D-CTA for the diagnosis of coronary ischemic disease and support its use for the preoperative evaluation of elderly lung cancer patients.

One limitation of our present study is that coronary angiography was not performed in all patients; consequently, the number of false-negatives using this 3D-CTA diagnostic method is unclear. However, none of our patients found to have no coronary stenosis by 3D-CTA in the preoperative period had vascular complications after surgery, further supporting the usefulness of 3DCTA as a screening tool for coronary disease in elderly patients before performing surgery for lung tumors.

\section{Conclusions}

In brief, the present study suggests the usefulness of 3DCTA for the preoperative diagnosis of coronary ischemic disease in elderly lung cancer patients.

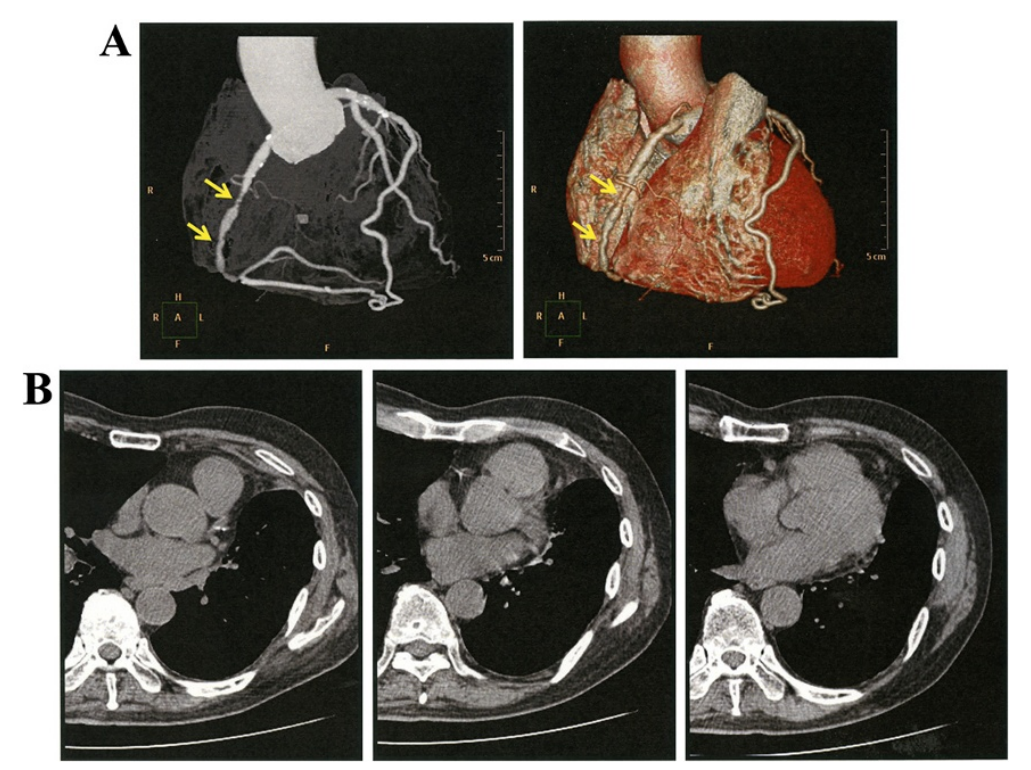

Figure 1 3D-CTA and conventional CT findings. Multiple areas with coronary stenosis (arrows) visualized by 3D-CTA (A) in an 82-year-old male patient with calcification grade 1 diagnosed by conventional CT (B). 


\section{Consent}

Written informed consent was obtained from the patient for the publication of this report and any accompanying images.

\section{Competing interest}

None of the authors had any competing interests regarding the results reported in this study.

\section{Authors' contributions}

FW participated in the design of the present study and prepared the first draft of the manuscript. OH, CNDG, Kl, MN, MO and HM participated in data collection and analysis. YM, MT, HS and ECG participated in the acquisition of the patients' medical records. IY participated in the acquisition of medical records and coordinated the whole study. All authors read and approved the final manuscript.

\section{Author details \\ ${ }^{1}$ Respiratory Center, Matsusaka Municipal Hospital, Tonomachi 1550, Matsusaka City, Mie 515-8544 Japan. ${ }^{2}$ Department of Radiology, Matsusaka Municipal Hospital, Tonomachi 1550, Matsusaka City, Mie 515-8544 Japan. ${ }^{3}$ Department of Cardiovascular Medicine, Matsusaka Municipal Hospital, Tonomachi 1550, Matsusaka City, Mie 515-8544 Japan. ${ }^{4}$ Department of Immunology, Mie University Faculty and Graduate School of Medicine, Edobashi 2-174Mie 514-8507 Tsu City, Japan. ${ }^{5}$ Department of General Thoracic and Cardiovascular Surgery, Mie University School of Medicine, 2-174 EdobashiMie 514-8507 Tsu City, Japan.}

Received: 27 May 2013 Accepted: 7 July 2013

Published: 20 July 2013

\section{References}

1. Christensen K, Doblhammer G, Rau R, Vaupel JW: Ageing populations: the challenges ahead. Lancet 2009, 374:1196-1208.

2. Lunenfeld B, Stratton P: The clinical consequences of an ageing world and preventive strategies. Best Pract Res Clin Obstet Gynaecol. doi:10.1016/j. bpobgyn.2013.02.005. in press.

3. Ma E, Iso H, Takahashi H, Yamagishi K, Tanigawa T: Age-period-cohort analysis of mortality due to ischemic heart disease in Japan, 1955 to 2000. Circ J 2008, 72:966-972.

4. Goldstraw P, Ball D, Jett JR, Le-Chevalier T, Lim E, Nicholson AG, Shepherd FA: Non-small-cell lung cancer. Lancet 2011, 378:1727-1740.

5. Shin $H R$, Carlos MC, Varghese C: Cancer control in the Asia Pacific region: current status and concerns. Jpn J Clin Oncol 2012, 42:867-881.

6. Van-Meerbeeck JP, Fennell DA, De-Ruysscher DK: Small-cell lung cancer. Lancet 2011, 378:1741-1755.

7. Murohara T, Ahiko T, Doi Y, Hanioka T, Higaki J, Hirano T, lida M, Ishii M, Kaji M, Kinoshita K, Mochizuki-Kobayashi Y, Nagai A, Saku K, Takahashi Y, Takano T, Yanase M, Yosizawa N, Kamiyama Y, Kawakami M, Kawane H, Matsumura Y, Nakamura M, Nakamura Y, Nakata Y, Shibata T, Sono J, Tsuboi M, Yamato H, Daida H, Ito T, et al: Guidelines for Smoking Cessation (JCS 2010): digest version. Circ J 2012, 76:1024-1043.

8. Kaira K, Takahashi T, Murakami H, Tsuya A, Nakamura Y, Naito T, Endo M, Yamamoto N: Long-term survivors of more than 5years in advanced nonsmall cell lung cancer. Lung Cancer 2010, 67:120-123.

9. Cunningham AJ: Myocardial ischemia: association with perioperative cardiac morbidity. Yale J Biol Med 1993, 66:339-348.

10. Seki M, Kashimoto S, Nagata O, Yoshioka H, Ishiguro T, Nishimura K, Honda O, Sakamoto A, Omi A, Ogihara Y, Fujimoto K, Iwade M, Yamada T, Nomura M, Takeda J: Are the incidences of cardiac events during noncardiac surgery in Japan the same as in the United States and Europe? Anesth Analg 2005, 100:1236-1240.

11. Ueshima K, Oba K, Yasuno S, Fujimoto A, Tanaka S, Ogihara T, Saruta T, Nakao K: Influence of coronary risk factors on coronary events in Japanese high-risk hypertensive patients:primary and secondary prevention of ischemic heart disease in a subanalysis of the Candesartan Antihypertensive Survival Evaluation in Japan (CASE-J) trial. Circ J 2011, 75:2411-2416

12. Kumar R, McKinney WP, Raj G, Heudebert GR, Heller HJ, Koetting M, McIntire DD: Adverse cardiac events after surgery: assessing risk in a veteran population. J Gen Intern Med 2001, 16:507-518.
13. American College of Cardiology/American Heart Association Task Force on Practice Guidelines (Writing Committee to Revise the 2002 Guidelines on Perioperative Cardiovascular Evaluation for Noncardiac Surgery), American Society of Echocardiography, American Society of Nuclear Cardiology, Heart Rhythm Society, Society of Cardiovascular Anesthesiologists, Society for Cardiovascular Angiography and Interventions, Society for Vascular Medicine and Biology, Society for Vascular Surgery, Fleisher LA, Beckman JA, Brown KA, Calkins H, Chaikof E, Fleischmann KE, Freeman WK, Froehlich JB, Kasper EK, Kersten JR, Riegel B, Robb JF, Smith SC Jr, Jacobs AK, Adams CD, Anderson JL, Antman EM, Buller CE, Creager MA, Ettinger SM, Faxon DP, Fuster $V$, et al: ACC/AHA 2007 guidelines on perioperative cardiovascular evaluation and care for noncardiac surgery. Executive summary: a report of the American College of Cardiology/American Heart Association Task Force on Practice Guidelines (Writing Committee to Revise the 2002 Guidelines on Perioperative Cardiovascular Evaluation for Noncardiac Surgery). Anesth Analg 2008, 106:685-712.

14. Kyo S, Imanaka K, Kurosawa H, Masuda M, Miyata T, Morita K, Nomura M, Sawa Y, Sueda T, Tabayashi K, Takamoto S, Ueda Y, Yozu R, Koyama I, Kudo M, Matsumiya G, Morota T, Orihashi K, Oshima H, Saiki Y, Saito S, Sakamoto Y, Imazeki T, Kawazoe K, Kuro M, Matsuzaki M, Nagai R, Yamamoto F, JCS Joint Working Group: Guidelines for perioperative cardiovascular evaluation and management for noncardiac surgery (JCS 2008): digest version. Circ J 2011, 75:989-1009.

15. Hoeks SE, Poldermans D: European Society of Cardiology 2009 guidelines for preoperative cardiac risk assessment and perioperative cardiac management in noncardiac surgery: key messages for clinical practice. Pol Arch Med Wewn 2010, 120:294-299.

16. Sun JZ, Maguire D: How to prevent perioperative myocardial injury: the conundrum continues. Am Heart J 2007, 154:1021-1028.

17. Devereaux PJ, Goldman L, Cook DJ, Gilbert K, Leslie K, Guyatt GH: Perioperative cardiac events in patients undergoing noncardiac surgery: a review of the magnitude of the problem, the pathophysiology of the events and methods to estimate and communicate risk. CMAJ 2005, 173:627-634.

18. Nagayoshi Y, Kawano H, Kojima S, Soejima H, Kaikita K, Nakayama M Sumida H, Sugiyama S, Ogawa H: Significance of coronary vasospasm in the perioperative management of non-cardiac surgery. Circ J 2012, 76:1965-1971

19. Choi JH, Song YB, Hahn JY, Choi SH, Gwon HC, Cho JR, Jang Y, Choe Y: Three-dimensional quantitative volume try of chronic total occlusion plaque using coronary multidetector computed tomography. Circ J 2011, 75:366-375.

20. Dey D, Schepis T, Marwan M, Slomka PJ, Berman DS, Achenbach S: Automated three-dimensional quantification of noncalcified coronary plaque from coronary CT angiography: comparison with intravascular US. Radiology 2010, 257:516-522.

21. Imazeki T, Sato Y, Inoue F, Anazawa T, Tani S, Matsumoto N, Takayama T, Uchiyama T, Saito S: Evaluation of coronary artery remodeling in patients with acute coronary syndrome and stable angina by multislice computed tomography. Circ J 2004, 68:1045-1050.

22. Kumamaru KK, Hoppel BE, Mather RT, Rybicki FJ: CT angiography: current technology and clinical use. Radiol Clin North Am 2010, 48:213-235. vii.

23. Fleisher LA, American College of Cardiology/American Heart Association: Cardiac risk stratification for noncardiac surgery: update from the American College of Cardiology/American Heart Association 2007 guidelines. Cleve Clin J Med 2009, 76(Suppl 4):S9-S15.

\section{doi:10.1186/1477-7819-11-164}

Cite this article as: Watanabe et al.: Three-dimensional computed tomography angiography for the preoperative evaluation of coronary artery disease in lung cancer patients. World Journal of Surgical Oncology 2013 11:164 